\title{
Late development of a large intrahepatic fistula after "closure" of an atrial septal defect
}

\author{
Albrecht Beitzke, MD, ${ }^{\mathrm{a}}$ Andreas Gamillscheg, MD, ${ }^{\mathrm{a}}$ Igor Knez, MD,${ }^{\mathrm{b}}$ Erich Sorantin, MD,${ }^{\mathrm{c}}$ \\ Robert Maier, MD, ${ }^{\mathrm{d}}$ and Martin Koestenberger, MD, ${ }^{\mathrm{a}}$ Graz, Austria
}

Partial hepatic vein (HV) exclusion as an alternative for baffle fenestration was used as a modification in patients undergoing the Fontan repair to achieve reduced systemic venous pressure and reduced serous effusions. ${ }^{1}$ Large intrahepatic venovenous communications, which can create massive arterial desaturation through an increasing right-toleft shunt caused by venous pressure differences between the caval system and the left atrium (LA), are known to develop after that type of operation. ${ }^{2,3}$ An intrahepatic venovenous fistula was diagnosed 25 years after surgical closure of an atrial septal defect (ASD). The fistula developed after inadvertent malposition of the patch, which directed inferior vena caval (IVC) flow to the LA and also divided hepatic venous return. The pressure difference between the IVC and LA to the right atrium (RA) obviously opened up hepatic vessels and thus created a large shunt from the IVC to the RA. There are close relations to similar findings after the Fontan operation with partial exclusion of HVs.

\section{CLINICAL SUMMARY}

A 30-year-old woman had undergone an operation for an ASD at the age of 5 years. Preoperative catheterization had revealed a $\mathrm{Qp} / \mathrm{Qs}$ ratio of 2.2 with normal pulmonary arterial pressure and resistance. According to the operative protocol, a large posterior-inferior defect was closed with a $3 \times 4-\mathrm{cm}$ patch. The postoperative course was uneventful, and no visible cyanosis was reported. No postoperative echocardiographic analysis was available. The patient was seen 25 years later when an enlarged liver led to ultrasonographic scanning of the abdomen. There was no visible cyanosis, and her oxygen saturation was $90 \%$. The investigation revealed a wide IVC with distended HVs and a tortuous intrahepatic vessel. Computed tomographic scanning showed drainage of the IVC into the LA, and magnetic resonance im-

\footnotetext{
From the Division of Pediatric Cardiology, Department of Pediatrics ${ }^{\mathrm{a}}$; the Division of Cardiac Surgery, Department of Surgery ${ }^{\text {b }}$ t the Division of Pediatric Radiology, Department of Radiology ${ }^{c}$; and the Division of Cardiology, Department of Internal Medicine, ${ }^{\mathrm{d}}$ Medical University of Graz, Graz, Austria.

Disclosures: None.

Received for publication July 16, 2008; revisions received Sept 12, 2008; accepted for publication Oct 16, 2008; available ahead of print Feb 23, 2009.

Address for reprints: Albrecht Beitzke, MD, Klinische Abteilung für Pädiatrische Kardiologie, Univ.-Klinik für Kinder- und Jugendheilkunde, Auenbruggerplatz 30, A-8036 Graz, Austria (E-mail: albrecht.beitzke@klinikum-graz.at).

J Thorac Cardiovasc Surg 2010;139:e43-5

$0022-5223 / \$ 36.00$

Copyright $₫ 2010$ by The American Association for Thoracic Surgery

doi:10.1016/j.jtcvs.2008.10.023
}
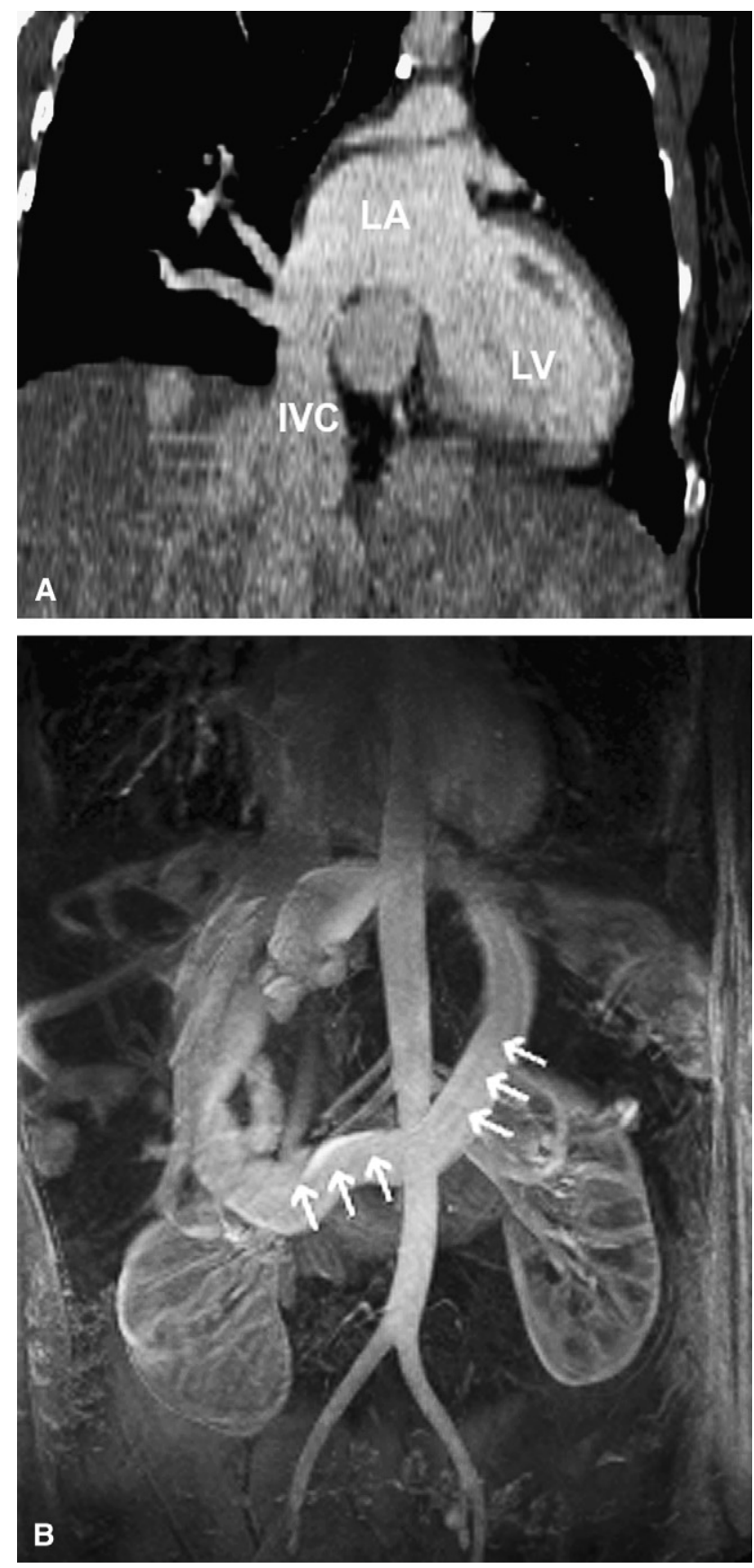

FIGURE 1. A, Contrast-enhanced electron beam computed tomography. The inferior vena cava drains into the left atrium. The right pulmonary veins enter the left atrium. $I V C$, Inferior vena cava; $L A$, left atrium; $L V$, left ventricle. B, Magnetic resonance angiography: 3-dimensional maximum intensity reconstruction. White arrows indicate the large venovenous fistula. 

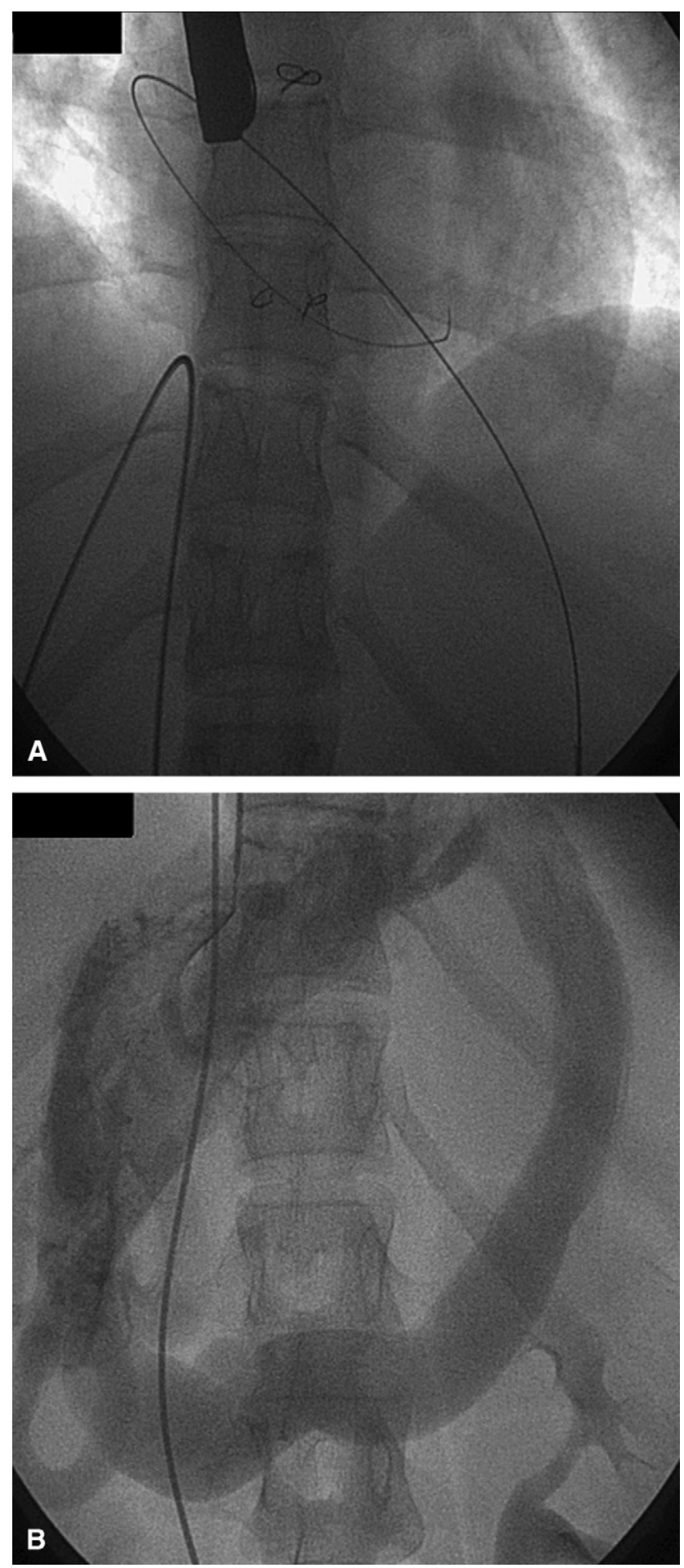

FIGURE 2. Cardiac catheterization, anteroposterior view. A, Passage of a guidewire from right-sided to left-sided hepatic veins into the right atrium and right ventricle. $\mathrm{B}$, Contrast injection into a right hepatic vein. Filling of the large venous vessel toward left-sided veins and the right atrium.

aging demonstrated the huge intrahepatic vessel connecting right- and left-sided HVs (Figure 1). Cardiac catheterization revealed a mean pressure of $12 \mathrm{~mm} \mathrm{Hg}$ in the IVC and LA compared with $8 \mathrm{~mm} \mathrm{Hg}$ in the RA. Pulmonary arterial pressure and vascular resistance were normal. The catheter could not only be passed from the IVC to the LA but also into the RA and right ventricle (RV) through the large venous vessel, which connected right- and left-sided HVs (Figure 2, A). Contrast injection into the IVC showed the contrast not only entering the LA but also a passage of contrast through the liver to the RA. The contrast was actually siphoned away from the IVC into the fistula, thus creating a large shunt to the RA (Figure 2, B). The RA and RV were also supplied by the superior vena cava. Pulmonary veins were normally connected to the LA. At reoperation, the interatrial septum, which had divided the hepatic venous return into right-sided veins connecting to the IVC and left-sided veins connecting to the RA, was removed. A new patch to close the defect and redirect all $\mathrm{HV}$ orifices, as well as the IVC to the RA, was implanted. The postoperative course was uneventful, and echocardiographic analysis showed an intact atrial septum and normally connected systemic and pulmonary veins. The patient was seen in 2008 in our outpatient clinic. She was fine, her oxygen saturation was $95 \%$, and the RV pressure was calculated to be $30 \mathrm{~mm} \mathrm{Hg}$.

\section{DISCUSSION}

In our patient the exact cardiac anatomy apparently had not been evaluated well before closing the ASD in 1978 . We assume that it could have been an inferior sinus venosus defect. $^{4,5}$ The patch had probably inadvertently been misplaced to connect the IVC to the LA and also divided the hepatic venous return into a right-sided part to the IVC and a left-sided part that connected to the RA. The patient had no immediate complaints and no visible cyanosis. Assuming that a hepatic fistula developed slowly, postoperative cyanosis should have been noticed. However, we cannot exclude that an additional congenital hepatic fistula was present at the time of the first operation. In addition, a large Eustachian valve might sometimes be mistaken as a remnant of the atrial septum and in the absence of parts of the inferior atrial septum might be connected falsely to the upper rim of the septum, thus creating a direct IVC-LA communication. ${ }^{6}$ With an oxygen saturation of $90 \%$ at the age of 30 years, the large venovenous intrahepatic shunt from the IVC toward the functional RA probably prevented a higher degree of desaturation because a large amount of IVC blood actually reached the RA through the hepatic fistula. In the Fontan circulation any residual connection between the systemic and pulmonary venous system has the potential for progressive enlargement. The development of hepatic venous anomalies, which probably develop through a pure pressure difference between the systemic and pulmonary venous circulation, can sometimes lead to massive cyanosis. ${ }^{2,3}$ Although we do not know exactly how the patch was placed and whether an Eustachian valve was present at the time of the operation in our case, the same kind of fistula developed because of LA 
and RA pressure differences caused by the inadvertently misconnected IVC. This case stresses the role of intraoperative transesophageal echocardiographic analysis even in simple cases, such as an ASD.

\section{References}

1. Jacobs ML, Norwood WI. Fontan operation: influence of modifications on morbidity and mortality. Ann Thorac Surg. 1994;58:945-52.
2. Reed MK, Leonard SR, Zellers TM, Hisashi N. Major intrahepatic veno-venous fistulas after a modified Fontan operation. Ann Thorac Surg. 1996;61:713-5.

3. Schneider DJ, Banerjee A, Mendelson MM, Norwood WI. Hepatic venous malformation after modified Fontan procedure with partial hepatic vein exclusion. Ann Thorac Surg. 1997;63:1177-9.

4. Al Zaghal AM, Li J, Anderson RH, Lincoln C, Shore D, Rigby ML. Anatomical criteria for the diagnosis of sinus venosus defects. Heart. 1997;78:298-304.

5. Gaynor JW. Management of sinus venosus defects. Semin Thorac Cardiovasc Surg Pediatr Card Surg Annu. 2006;35-9.

6. Fouty BW, Lynch DA, Fontenot AP, Schwarz MI. Hypoxemia explained 36 years later. Chest. 2001;120:1739-40.

\title{
Optimism derived from 7.5 years of continuous-flow circulatory support
}

\author{
Stephen Westaby, PhD, ${ }^{\mathrm{a}}$ Adrian Banning, MD, ${ }^{\mathrm{a}}$ Desley Neil, MD, ${ }^{\mathrm{b}}$ Philip Poole-Wilson, F Med Sci, ${ }^{\mathrm{c}}$ and \\ O. Howard Frazier, MD, ${ }^{\mathrm{d}}$ Oxford, Birmingham, and London, United Kingdom; and Houston, Tex
}

Severely symptomatic heart failure is increasingly common as the population ages. Both prognosis and quality of life are poor. These patients have limited options. Few are eligible for cardiac transplantation because of age or the common transplant comorbidities of pulmonary hypertension and renal impairment. In New York Heart Association (NYHA) class IV patients, ventricular resynchronization therapy provides only marginal benefit that is insufficient to improve quality of life. ${ }^{1}$ Lifetime circulatory support has a firm evidence base in the REMATCH trial. ${ }^{2}$ Because of the complication rates in first-generation left ventricular assist devices (LVADs), the compelling argument for an off-the-shelf solution for advanced heart failure has been slow to progress.

In 2000, we reported the first implantation of a new miniaturized rotary blood pump with a novel power-delivery system designed for permanent use. ${ }^{3}$ At the time, there was skepticism about the ability of a nonpulsatile LVAD to sustain end-organ function on a long-term basis. In fact, the patient became the world's longest circulatory support survivor. We now describe the autopsy findings to conclude this experience.

\footnotetext{
From the Departments of Cardiac Surgery and Cardiology, ${ }^{a}$ John Radcliffe Hospital, Oxford, United Kingdom; the University Department of Pathology, ${ }^{\mathrm{b}}$ Selly Oak Hospital, Birmingham, United Kingdom; the Department of Cardiology, ${ }^{\mathrm{c}}$ Royal Brompton Hospital, London, United Kingdom; and the Department of Cardiac Surgery, ${ }^{\mathrm{d}}$ The Texas Heart Institute, Houston, Tex.

Disclosures: None.

Received for publication April 29, 2008; revisions received May 19, 2008; accepted for publication May 19, 2008; available ahead of print March 18, 2009.

Address for reprints: Stephen Westaby, PhD, Department of Cardiac Surgery, John Radcliffe Hospital, Headley Way, Headington, Oxford OX3 9DU, United Kingdom (E-mail: swestaby@AHF.org.uk).

J Thorac Cardiovasc Surg 2010;139:e45-7

0022-5223/\$36.00

Copyright (C) 2010 by The American Association for Thoracic Surgery

doi:10.1016/j.jtcvs.2008.05.072
}

\section{CLINICAL SUMMARY}

The patient was a 60 -year-old man with a 7-year history of symptomatic idiopathic dilated cardiomyopathy leading to breathlessness at rest, pitting edema to the thighs, ulcerated legs, and ascites, despite maximum medical therapy. Left ventricular ejection fraction was less than $10 \%$, with a cardiac index of $1.81 \mathrm{~L} \cdot \mathrm{min}^{-1} \cdot \mathrm{m}^{-2}$. Maximal oxygen consumption was $5.7 \mathrm{~mL} \cdot \mathrm{kg}^{-1} \cdot \min ^{-1}$ during exercise, and pulmonary vascular resistance was 7 Wood units. With a single functioning kidney and a creatinine clearance of $38 \mathrm{~mL} /$ min, he was not accepted for the transplant wait listing.

The Jarvik 2000 axial flow pump (Jarvik Heart, Inc, New York, NY) was implanted directly into the apex of the left ventricle with a Dacron graft to the descending thoracic aorta (Figure 1, A). The power-delivery system used a titanium pedestal screwed into the skull, providing a plug into which the external power line, battery, and controller were attached (Figure 1,B). ${ }^{4}$ Postoperative management included anticoagulation with warfarin to maintain an international normalized ratio of between 2.5 and 3.0, together with continuous pharmacologic afterload reduction. Mean blood pressure was between 80 and $90 \mathrm{~mm} \mathrm{Hg}$, usually with a pulse pressure of 10 to $15 \mathrm{~mm} \mathrm{Hg}$. At a pump rotor speed of 10,000 rpm, resting cardiac output was between 4.5 and $5.5 \mathrm{~L} /$ min. Over 3 months, the patient returned to NYHA class I.

He led a very active and productive life for 7.5 years. After the perioperative period, less than $5 \%$ of the follow-up duration was spent in the hospital. There were no pump malfunctions or thromboembolic complications. External cables and batteries were exchanged on numerous occasions through wear and tear. The skull pedestal remained infection free. Staphylococcal septicemia followed nasal cauterization for epistaxis but was successfully treated with a 3-month 